\title{
Identity of viridans streptococci isolated from cases of infective endocarditis
}

\author{
C. W. I. DOUGLAS, J. HEATH, K. K. HAMPTON* and F. E. PRESTON* \\ Department of Oral Pathology, School of Clinical Dentistry, University of Sheffield and "Department of \\ Haematology, Royal Hallamshire Hospital, Sheffield
}

\begin{abstract}
Summary. The oral streptococci have undergone considerable taxonomic revision in recent years but there is still little information concerning associations between the newly defined species and disease. This study examined the identities of 47 strains of oral streptococci collected from 42 confirmed cases of infective endocarditis. By means of recently described physiological schemes, the most common species identified were Streptococcus sanguis sensu stricto $(31.9 \%)$, S. oralis $(29.8 \%)$ and $S$. gordonii $(12.7 \%)$. Other related species including $S$. mitis and " $S$. parasanguis" were less common. This indicates that attention should be focused on $S$. sanguis sensu stricto and $S$. oralis when considering possible pathogenic mechanisms involved in viridans streptococcal endocarditis.
\end{abstract}

\section{Introduction}

Oral streptococi are among the most common causes of infective endocarditis, ${ }^{1-5}$ and of these, Streptococcus sanguis, " $S$. mitior" and $S$. mutans are isolated most frequently. ${ }^{1-5}$ However, recent taxonomic studies of these organisms have resulted in the recognition of several new species as well as the redefinition of older ones and many of the earlier endocarditis isolates now carry different names. For example, $S$. sanguis is now divided into $S$. sanguis sensu stricto and $S$. gordonii. ${ }^{6}$ A streptococcus, closely related to $S$. sanguis, and characterised by having tufts of surface fibrils, has been named S. crista. " S. mitior" is no longer described as such and has been re-named $S$. mitis. ${ }^{6}$ Strains described previously as "dextranpositive mitior" are now " $S$. oralis" $", 8$ whilst " $S$. milleri," previously an ill-defined heterogeneous group of organisms, has been divided among three species$S$. anginosus, $S$. intermedius and $S$. constellatus. ${ }^{9}$ Also, some strains originally thought to belong to the "milleri group", but which could not be classified as any of the above species, have now been grouped into a new species, "S. parasanguis", related to $S$. sanguis. ${ }^{10}$ $S$. vestibularis is a new species similar to $S$. salivarius. ${ }^{11}$ Finally, the "mutans streptococci" are now divided into seven species. ${ }^{12}$

Although such changes have largely ended the state of taxonomic confusion that has been characteristic of the viridans streptococci for many years, it is im-

Received 12 Feb. 1993; accepted 18 Feb. 1993

Correspondence should be sent to Dr C. W. I. Douglas, Department of Oral Pathology, School of Clinical Dentistry, Claremont Crescent, Sheffield S10 2TA. portant that the association of individual species with disease be re-assessed in relation to recognition of important pathogenic traits.

The aim of the present study was to determine the identities of oral streptococci isolated from cases of infective endocarditis in the light of the new taxonomy.

\section{Materials and methods}

\section{Bacterial strains}

Forty-seven strains of viridans streptococci were collected from several centres in the UK and from one centre in Germany. These were isolated from 42 confirmed cases of endocarditis, but the clinical information was available for only 17 patients and, therefore, we have no knowledge of patients' symptoms or previous medical history, such as presence of prosthetic valves and recent dental treatment. Strains were stored freeze-dried.

\section{Identification}

Growth from a blood-agar plate was removed with a sterile cotton swab. Half the growth was resuspended in $1 \mathrm{ml}$ of sterile water and the other half in $1 \mathrm{ml}$ of $0 \cdot 1 \mathrm{M}$ Tris- $\mathrm{HCl}, \mathrm{pH} 7 \cdot 0$. Organisms suspended in water were tested for their ability to ferment raffinose, inulin, $\mathrm{N}$-acetylglucosamine and mannitol, and for hydrolysis of aesculin and arginine. For fermentation reactions, sugars $(1 \% \mathrm{w} / \mathrm{v})$ were included in a basal medium comprising Purple Broth Base (Difco) $16 \mathrm{~g} / \mathrm{L}$, Thioglycollate Broth (Difco) $24 \mathrm{~g} / \mathrm{L}$ and yeast extract (Lab M) $5 \mathrm{~g} / \mathrm{L}, \mathrm{pH} 7 \cdot 2$. Broths were incubated in $\mathrm{CO}_{2}$ at 
Table I. Identification scheme for viridans streptococci

\begin{tabular}{|c|c|c|c|c|c|c|c|c|c|c|}
\hline \multirow{2}{*}{ Test } & \multicolumn{10}{|c|}{ Results characteristic of species } \\
\hline & S.sI & S.sII & S.sIII & S.o. & S.p. & S.g. & S.mi & S.sl & S.mu & S.b \\
\hline Amylase binding & - & - & - & - & + & + & + & \pm & - & - \\
\hline Hydrolysis of: & & & & & & & & & & \\
\hline aesculin & + & + & - & - & - & + & - & + & + & + \\
\hline arginine & + & + & + & - & + & + & - & - & - & - \\
\hline Acid from: & & & & & & & & & & \\
\hline raffinose & + & + & - & + & V & - & + & V & + & + \\
\hline inulin & + & V & $\mathrm{V}$ & - & - & + & V & V & + & + \\
\hline $\mathrm{N}$-acetylglucosamine & + & + & + & + & + & + & + & + & + & + \\
\hline mannitol & - & - & - & - & - & - & - & - & + & + \\
\hline $\begin{array}{l}\text { Enzymes: } \\
\text { sialidase }\end{array}$ & - & - & & $t$ & & & $\mathbf{V}$ & - & & - \\
\hline $\begin{array}{l}\text { sialidase } \\
\mathrm{N} \text {-acetylgalactosaminidase }\end{array}$ & - & $\overline{-}$ & $\overline{-}$ & $\begin{array}{l}t \\
+\end{array}$ & $\bar{t}$ & $\overline{\mathbf{V}}$ & 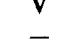 & $\begin{array}{l}- \\
-\end{array}$ & $\begin{array}{l}- \\
-\end{array}$ & $\overline{\mathrm{v}}$ \\
\hline$\beta$-fucosidase & - & + & $\bar{v}$ & - & V & - & - & V & - & $\mathrm{V}$ \\
\hline$\alpha$-glucosidase & - & - & - & + & + & V & + & V & + & V \\
\hline$\alpha$-arabinosidase & - & - & - & - & V & - & - & + & - & - \\
\hline $\mathrm{N}$-acetylglucosaminidase & - & V & + & + & + & + & - & - & - & + \\
\hline
\end{tabular}

,$+>80 \%$ positive;,$-<15 \%$ positive; $\mathrm{V}, 15-80 \%$ positive. (Results for table assembled from references $1,3,4,5,15$ ).

S.s, S. sanguis biotypes I, II, III; S.o, S. oralis; S.p, "S. parasanguis"; S.g., S. gordonii; S.mi, S. mitis; S.sl, S. salivarius; S.mu., S. mutans; S.b, S. bovis.

$37^{\circ} \mathrm{C}$ and assessed after 24,48 and $72 \mathrm{~h}$. Aesculin hydrolysis and the production of ammonia from arginine were tested by the method described by Bisset and Davis $;{ }^{13}$ the production of ammonia from arginine was detected by the addition of Nessler's reagent.

Organisms suspended in Tris buffer were assessed for the constitutive enzymes $\mathrm{N}$-acetylneuraminidase, $\beta$-fucosidase, $\mathrm{N}$-acetylgalactosaminidase, $\alpha$-glucosidase, $\alpha$-arabinosidase and $\mathrm{N}$-acetylglucosaminidase in tests with the fluorogenic 4-methylumbelliferyl (MU) substrates 2'-4-MU- $\alpha$-D-N-acetylneuraminic acid, 4-MU- $\beta$-D-fucoside, 4-MU-N-acetyl-galactosaminide, 4-MU- $\alpha$-D-glucoside, (4-MU)- $\alpha$-L-arabinoside and 4-MU-N-acetyl-glucosaminide respectively (Sigma). Substrates were dissolved in a small volume of dimethyl sulphoxide and diluted for use into $0 \cdot 1 \mathrm{M}$ Tris- $\mathrm{HCl}, \mathrm{pH} 7 \cdot 5$, to a final concentration of $100 \mu \mathrm{g} / \mathrm{ml}$.

Ability to bind salivary amylase was assessed by the method described by Douglas. ${ }^{14}$ The scheme used for the identification of strains was that described by Beighton et al..$^{15}$ supplemented by that of Douglas $e t$ $a l^{16}$ for amylase-binding discrimination (table I).

\section{Results}

The numbers of isolates from endocarditis cases ascribed to each species are shown in table II. The 47 strains were divided among eight species. S. sanguis $(15$ strains, $32 \%$ ) and $S$. oralis $(14,29.8 \%$ ) were the two most common, followed by $S$. gordonii $(6,12 \cdot 7 \%)$. $S$. bovis and the remaining oral species were isolated relatively infrequently. Biotypes 2 and 3 of $S$. sanguis were more common than biotype 1 .

The majority ( $82 \%)$ of strains fitted the identification scheme exactly and the remaining strains were identified to within one or two test reactions. In the latter cases, greater emphasis was put on the results of tests that had been reported as $100 \%$ reactions for particular species. ${ }^{6,15,16}$ One strain could not be identified.

\section{Discussion}

There have been several studies on the microbial aetiology of infective endocarditis but these neither speciated the viridans streptococci nor were the schemes employed capable of differentiating the new species. Table III shows a summary of the results of five such studies in which $S$. sanguis and "S. mitior" were consistently the species most frequently isolated. With the exception of the study by Parker and Ball, ${ }^{17}$ no information has been given on the physiological characteristics of the strains isolated, and so it is not possible to deduce their likely identities in the light of the new taxonomy. The results of this study differ from previous findings mainly in that $S$. oralis was found to be a frequent isolate from endocarditis cases and $S$. mitis and $S$. mutans were uncommon. However, in line with previous reports, $S$. sanguis proved to be the numerically dominant species and must, therefore, still be considered the most important of the oral streptococci causing infective endocarditis. The closely related species, $S$. gordonii, which would have been classified as $S$. sanguis in previous studies, was the third most prominent group, although it represented less than half the number of $S$. sanguis sensu stricto isolates. Although it could be said that the isolates studied here represented a biased collection, this is unlikely as approximately half of them came from district hospitals rather than from regional referral centres.

Parker and Ball have given a full description of the strains isolated from endocarditis in their study. ${ }^{17}$ 
Table II. Identities of streptococcal isolates

\begin{tabular}{|c|c|c|}
\hline Species & \multicolumn{2}{|c|}{ Number $(\%)$ of isolates } \\
\hline S. sanguis biotype 1 & 3) & $(6.4) \boldsymbol{\lambda}$ \\
\hline S. sanguis biotype 2 & $6\} 15$ & $(12 \cdot 7)\}(31 \cdot 9)$ \\
\hline S. sanguis biotype 3 & $6 \sqrt{3}$ & $(10 \cdot 6)$ \\
\hline S. oralis & 14 & $(29 \cdot 8)$ \\
\hline S. gordonii & 6 & $(12 \cdot 7)$ \\
\hline S. bovis & 3 & $(6 \cdot 4)$ \\
\hline "S. parasanguis" & 2 & $(4 \cdot 2)$ \\
\hline S. mitis & 2 & $(4 \cdot 2)$ \\
\hline S. mutans & 2 & $(4 \cdot 2)$ \\
\hline S. salivarius & 2 & $(4 \cdot 2)$ \\
\hline Unidentified & 1 & $(2 \cdot 1)$ \\
\hline
\end{tabular}

Strains designated "dextran-positive mitior" should now be called $S$. oralis and it is likely that some of the " $S$. mitior" strains might also be described as $S$. oralis, despite giving negative results in tests for dextran, the major differentiating factor used. Kilian et al. ${ }^{6}$ reported that $22 \%$ of $S$. oralis strains failed to produce dextran detectable by an alcohol precipitation test $;^{18}$ thus, if a similar proportion of " $S$. mitior" strains in the study of Parker and Ball proved to be dextrannegative $S$. oralis, this would become an important species in their series. It is probable that $S$. oralis has been under-reported in previous studies of infective endocarditis.

Because $S$. sanguis, $S$. oralis and, possibly, $S$. gordonii are frequently isolated from cases of infective endocarditis, it is tempting to speculate that they have pathogenic features particularly relevant to the disease. All three species produce extracellular dextran from sucrose and there is evidence to suggest that dextran promotes adhesion to thrombus in the rabbit endocarditis model. ${ }^{19}$ Also, it has been shown that $S$. sanguis strains are able to aggregate human platelets in vitro more effectively than other species $;{ }^{20}$ this may enable these organisms to contribute to thrombus formation on endothelial surfaces. ${ }^{21}$ Studies on one strain of $S$. gordonii have shown that it can attach to fibronectin when this is adsorbed to a collagen sur-
Table III. Reports on the microbial aetiology of infective endocarditis (percentages of isolates)

\begin{tabular}{|c|c|c|c|c|c|}
\hline Organism & $\begin{array}{l}\text { Bayliss } \\
\text { et } a l^{1}\end{array}$ & $\begin{array}{c}\text { Roberts } \\
\text { et al. }\end{array}$ & Young ${ }^{3}$ & $\begin{array}{l}\text { Manford } \\
\text { et al. }{ }^{4}\end{array}$ & $\begin{array}{c}\text { Parker } \\
\text { and } \\
\text { Ball }^{17}\end{array}$ \\
\hline \multicolumn{6}{|l|}{ Streptococci } \\
\hline$\beta$-haemolytic & 1 & 1 & 5 & - & 5 \\
\hline S. sanguis & 5 & 24 & 21 & 23 & 17 \\
\hline "S. mitior" & 5 & 31 & 19 & 13 & 21 \\
\hline S. mutans & 2 & 7 & 8 & 3 & 14 \\
\hline "S. miller" & 2 & 4 & 5 & 3 & 5 \\
\hline S. salivarius & 1 & 1 & 4 & - & 1 \\
\hline S. bovis & 5 & 27 & - & - & 17 \\
\hline NVS* & 一 & 5 & - & - & - \\
\hline S. faecalis & 2 & 7 & 5 & 6 & 8 \\
\hline $\begin{array}{l}\alpha \text {-haemolytic } \\
\text { (not identified) }\end{array}$ & 33 & 1 & 43 & 10 & 11 \\
\hline Other organisms & 27 & 39 & 34 & 25 & - \\
\hline Culture negative & 9 & 3 & - & 5 & - \\
\hline
\end{tabular}

* NVS, nutritionally variant streptococci.

face, ${ }^{22}$ a situation that might be expected to prevail in an area of damaged endothelium. In contrast, little is known about potential pathogenic features of $S$. oralis that might be relevant to endocarditis, although the species has a significant glycosidase potential, including $\mathrm{N}$-acetyl-neuraminidase activity, and many plasma glycoproteins carry $\mathrm{N}$-acetylneuraminic acid groups. Also, S. sanguis biotypes 2 and 3, as defined by Beighton et al. ${ }^{15}$ exhibit more glycolytic activity than type 1 strains, and the former were more frequent isolates in this study than the latter. It may be that $S$. sanguis and $S$. oralis grow more successfully in plasma or thrombotic vegetations than other species of oral streptococci.

With improvements in taxonomy of the oral streptococci and the development of rapid physiological schemes for their identification, it is becoming possible to focus attention on pathogenic mechanisms of the organisms that are of greatest importance in infective endocarditis.

This work was funded by the British Heart Foundation, grant number $16 / 91$.

\section{References}

1. Bayliss R, Clark C, Oakley CM, Somerville W, Whitfield AGW, Young SEJ. The microbiology and pathogenesis of infective endocarditis. Brit Heart $J 1983$; 50: 513-519.

2. Roberts RB, Krieger AG, Schiller NL, Gross KC. Viridans streptococcal endocarditis: The role of various species, including pyridoxal-dependent streptococci. Rev Infect Dis 1979; 1 : 955-965.

3. Young SEJ. Etiology and epidemiology of infective endocarditis in England and Wales. J Antimicrob Chemother 1987; 20 Suppl A: 7-15.

4. Manford M, Matharu J, Farrington $K$. Infective endocarditis in a district general hospital. J R Soc Med 1992; 85: 262-266.

5. McCartney AC. Changing trends in infective endocarditis. $J$ Clin Pathol 1992; 45: 945-948.

6. Kilian M, Mikkelsen L, Henrichsen J. Taxonomic study of viridans streptococci: Description of Streptococcus gordonii sp. nov. and emended descriptions of Streptococcus sanguis (White \& Niven 1956), Streptococcus oralis (Bridge \& Sneath 1982) and Streptococcus mitis (Andrews \& Horder 1906). Int J Syst Bacteriol 1989; 39: 471-484.

7. Handley PS, Coykendall A, Beighton D, Hardie JM, Whiley RA. Streptococcus crista sp.nov., a viridans streptococcus with tufted fibrils, isolated from the human oral cavity and throat. Int J Syst Bacteriol 1991; 4: 543-547.

8. Bridge PD, Sneath PHA. Numerical taxonomy of Streptococcus. J Gen Microbiol 1983; 129 : 565-597.

9. Whiley RA, Beighton D. Emended descriptions and recognition of Streptococcus constellatus, Streptococcus intermedius, and Streptococcus anginosus as distinct species. Int J Syst Bacteriol 1991; 41: 1-5.

10. Whiley RA, Fraser HY, Douglas CWI, Hardie JM, Williams AM, Collins MD. Streptococcus parasanguis sp. nov., an 
atypical viridans Streptococcus from human clinical specimens. FEMS Microbiol Lett 1990; 68: 115-122.

11. Whiley RA, Hardie JM. Streptococcus vestibularis sp. nov. from the human oral cavity. Int J Syst Bacteriol 1988; 38: 335-339.

12. Coykendall AL. Classification and identification of the viridans streptococci. Clin Microbiol Rev 1989; 2: 315-328.

13. Bisset KA, Davis GHG. The microbial flora of the mouth. London, Heywood. 1960.

14. Douglas CWI. The binding of human salivary $\alpha$-amylase by oral strains of streptococcal bacterial. Arch Oral Biol 1983; 28: $567-573$.

15. Beighton D, Hardie JM, Whiley RA. A scheme for the identification of viridans streptococci. $J$ Med Microbiol $1991 ; 35$ : 367-372

16. Douglas CWI, Pease AA, Whiley RA. Amylase-binding as a discriminator among oral streptococci. FEMS Microbiol Lett 1990; 66: 193-198.
17. Parker MT, Ball LC. Streptococci and aerococci associated with systemic infection in man. J Med Microbiol 1976; 9: 275-302.

18. Gibbons RJ, Banghart SB. Synthesis of extracellular dextran by cariogenic bacteria and its presence in human dental plaque. Arch Oral Biol 1967; 12: 11-23.

19. Baddour LM, Christensen GD, Lowrance JH, Simpson WA. Pathogenesis of experimental endocarditis. Rev Infect Dis 1989 ; 11 : 3452-463.

20. Douglas CWI, Brown PR, Preston FE. Platelet aggregation by oral streptococci. FEMS Microbiol Lett 1990; 72, 63-68.

21. Herzberg MC, Brintzenhofe KL, Clawson CC. Aggregation of human platelets and adhesion of Streptococcus sanguis. Infect Immun 1983; 39: 1457-1469.

22. Lowrance JH, Hasy DL, Simpson WA. Adherence of Streptococcus sanguis to conformationally specific determinants in fibronectin. Infect Immun 1988; 56: 2279-2285. 